\title{
Computer and internet use by the undergraduate medical students of Bangladesh
}

\author{
Shaheen, M. M. ${ }^{1}$, Nahar, S. ${ }^{2}$, Talukder, M.H.K. ${ }^{3}$, Tasnim, S. ${ }^{4}$
}

\begin{abstract}
Background: A rising tide of information technology (IT) is sweeping through medical education providing learners with easier and more effective access to a wider variety and greater quantity of information.
\end{abstract}

Objectives: This descriptive cross sectional survey was done to explore status of computer and internet use by undergraduate medical students of Bangladesh.

Methods: 659 final year MBBS students of randomly selected eight medical colleges of Bangladesh were supplied with a pre tested self-administered questionnaire, seeking information regarding the use of computer and internet, in the period of July 2012 to June 2013.

Results: Majority (52\%) of the respondents were female. Almost $90 \%$ of the respondents had computer and internet access. 83\% had personal computer and almost two third of the sample used computers for more than 3 years. Majority used computer and internet more for non-academic activities like chatting, E mail, entertainment, collection of general information, reading newspaper and etc. The features used for academic purposes were multimedia/power point $(61.2 \%)$, internet literature search $(42.3 \%)$, presentations $(25.8 \%)$, and word processing $(23.2 \%)$. According to the research findings the most visited sites for academic purposes were Google, Wikipedia, Yahoo, Facebook and YouTube.

Conclusion: It is essential to improve the computer and IT knowledge in academics meanwhile reducing non-academic uses.

Key Words: Computer, Internet, Medical student, IT, Bangladesh

\section{Introduction}

Medical education has undergone profound changes due to recent technological advancements (Harden, 2002 and Davis \& Harden, 2001).

\footnotetext{
${ }^{1}$ Associate Professor (ENT)

Shaheed Suhrawardy Medical College, Dhaka, Bangladesh.

${ }^{2}$ Assistant Professor (Psychiatry),

National Institute of Mental Health, Dhaka, Bangladesh.

${ }^{3} \mathrm{TNP}-\mathrm{HRH}$

WHO Country Office, Bangladesh

${ }^{4}$ Director, Institute of Child and Mother Health, Dhaka, Bangladesh.

Corresponding Author:

Dr. MD. Mazharul Shaheen

Associate Professor, Dept of ENT \& Head-Neck Surgery

Shaheed Suhrawardy Medical College, Dhaka, Bangladesh.
}

Email:mazhar1047@yahoo.com
A rising tide of information technology (IT) is sweeping through it, providing learners easier and more effective access to a wider variety and greater quantity of information (Mooney \& Bligh, 1997).With rapid development in computer technology and the wide availability of the personal computers together with the internet and various medical literature retrieval applications, there is a positive impact on health care delivery system worldwide, particularly in the areas of disease control, diagnosis, patient management, teaching, research and training (Myers \& Mary, 2003 ; Feliciani, 2003).

Use of computerized information systems by medical professionals can improve the quality of care, enhance the use of evidence-based treatment, maintain and to update knowledge. Internet, as a vehicle for worldwide communication, is now one of the most important and instantaneous sources of 
information for students in institutions of higher learning throughout the world. It has also become a popular medium for delivering educational materials (Ajuwon, 2003). Problem and evidence based medicine, self-directed learning supposed to be the pillars of modern medicine and education system. The essence of these systems lies in the study of researches, literatures, experiments and it requires access to vast amount of information, which only computer and internet can provide.

Computer and related networks, webs are not only highly desirable but indeed a very necessary ingredient of modern health care. It is uniformly accepted among all jurisdictions. The ability of computer to capture and maintain patients' histories, examination findings, diagnoses, treatments, allergies, immunizations, results of investigations makes it possible for health providers to quickly and easily access this potentially lifesaving information at the point of care. Research on computer literacy focused on the question whether medical students were ready for the foreseeable omnipresence of computers in the future doctors' professional environments i.e. whether they possessed the necessary computer skills (Seago et al., 2002).

Skills in medical informatics and IT should be considered as core competencies of graduating physicians (Otto \& Kushniruk, 2009). One estimate suggested that by 2010 more than $30 \%$ of a physician's time will be spent using information technology tools (Skinner et al., 2003). But, there is a general lack of IT and medical informatics education in undergraduate medical Programme internationally and a similar lack of evidence regarding their appropriate use and effectiveness (Otto \& Kushniruk, 2009).

In contrast to its extensively acknowledged importance, computer access and computer related skills demonstrate a wide diversity, both regional and within students and faculties of the same institution (Virtanen \& Nieminen, 2002; Mattheos et al., 2001 and Walmsley et al., 2003). Educational institutions around the world have been increasingly confronting with the challenge to ensure mastery in computer and internet use among the future physicians (Poelmans et al., 2009). The availability of affordable computers and the advancement of information technology have resulted in our ability to access rapidly and effectively .Also, retrieve, analyse, share, and store large volumes of information pertinent to patient care and for learning process in a teaching hospital (Masood et al., 2010).

Medical colleges, particularly in the developed countries, have invested heavily in ICT, not only to deliver education, but also to improve the quality of services that health professionals provide (Kumar, 2012).Developing countries like Bangladesh, where a scarcity of human resources in the health sector is a serious problem, can be a particular beneficiary of computer and IT mediated medical service delivery. In fact, international organizations such as the United Nations (UN) and the World Health Organization (WHO) have acknowledged IT as a useful tool to address education in health care sector in developing countries (Drury, 2005).

In Bangladesh, current MBBS curriculum implemented in 2002, did not address computer and internet. But, our undergraduate medical students reacted and adapted to this academic resource sporadically with their own initiative. Moreover, observations on medical student's status of computer use and internet access are a few throughout the globe and no report is published in Bangladesh till date. Hence, this study was done to explore the current status of computer and internet use by the undergraduate medical students of Bangladesh. This baseline survey outcome would fill the gap of information and help to develop future strategies for curriculum revision, formulate plan to build our future physicians capable to cope with their "digital natives" around the Globe.

\section{Methodology}

This descriptive cross sectional study was conducted among 659 final year MBBS students of randomly selected eight medical colleges of Bangladesh during July 2012 to June 2013 using a pre tested self-administered semi-structured questionnaire. The study settings were i) Dhaka Medical College, Dhaka ii) MAG Osmani Medical College, Sylhet iii) Sir Salimullah Medical College, Dhaka iv) Armed Forces Medical College, Dhaka v) RagibRabeya Medical College, Sylhet vi) Dhaka National Medical College, Dhaka vii) Sylhet Women's Medical College, Sylhet viii) Shahabuddin Medical College, Dhaka. The questionnaire was distributed in the lecture class of the participants with prior permission from the teachers and was collected immediately after completion. Students' participation was voluntary. Confidentiality and anonymity were strictly maintained. All ethical 
issues were considered and necessary permission was taken from ethical committee of the Bangabandhu Sheikh Mujib Medical University before the data collection. Collected data were verified, compiled, tabulated and analyzed.

\section{Results}

Out of the 659 respondents of the survey, $52 \%$ were female and $48 \%$ were male, $83 \%$ had personal computer, $91 \%$ had computer access and $90 \%$ had internet access. Majority $(76.4 \%)$ of them used computers for more than 3 years.

Table-1: Uses of computer and Internet by the respondents

\begin{tabular}{llc}
\hline Uses of Computer $(\mathbf{n}=\mathbf{6 5 8})$ & Frequency & ${ }^{*}$ Percentage \\
& & 31.6 \\
\hline Literature searching & 208 & 37.8 \\
Email & 249 & 58.4 \\
Academic reading & 385 & 39.8 \\
Non-academic reading & 262 & 65.1 \\
Chatting (face book and others) & 429 & 18.4 \\
To prepare for assignments of the course & 121 & 10.2 \\
Others & 67 & 84.1 \\
\hline Uses of Internet $(\mathbf{n}=602)$ & & 75.9 \\
\hline Entertainment & 506 & 15.1 \\
General Information & 457 & 32.6 \\
Thesis and research & 91 & 7.5 \\
Reading newspaper & 196 & 45 \\
Others & & \\
\hline
\end{tabular}

${ }^{*}$ Responses are more than $100 \%$ due to multiple responses

About $65.1 \%$ of the respondents used computer for chatting (Facebook and others) and 58.4\% of the respondents used computers for academic reading. Majority of them used internet for entertainment $(84.1 \%)$ and collection of general information (75.9\%).

Table-2: Features of computers used and weekly average time spent in computer and internet for academic purposes

\begin{tabular}{lcc}
\hline $\begin{array}{l}\text { Features of computers used more in the pursuit of } \\
\text { studies }(\mathbf{n = 5 8 3})\end{array}$ & Frequency & * Percentage \\
Word processing & 135 & $23.2 \%$ \\
Multimedia/Power point & 356 & $61.2 \%$ \\
Internet literature search & 246 & $42.3 \%$ \\
Presentations & 150 & $25.8 \%$ \\
Data management & 31 & $5.3 \%$ \\
Others & 15 & $2.6 \%$ \\
\hline
\end{tabular}




\begin{tabular}{lcc}
\hline \multicolumn{2}{l}{ Weekly average time spent in computer and internet for academic purposes $(\mathbf{n}=\mathbf{5 6 7})$} \\
\hline Up to 3 hours/week & 292 & 51.5 \\
4-6 hours/week & 103 & 18.2 \\
7-9 hours/week & 47 & 8.3 \\
10 hours or more/week & 51 & 9.0 \\
Others & 74 & 13.1 \\
\hline
\end{tabular}

* Responses are more than $100 \%$ due to multiple responses

$61.2 \%$ of the sample used multimedia/power point, internet literature search was (42.3\%), presentations $(25.8 \%)$, and word processing (23.2\%). Weekly average time spent by the respondents with computer and internet for academic purposes were up to 3 hours (51.5\%), 4-6 hours (18.2\%) and 10 hours or more $(9.0 \%)$.

Table 3: Non-academic uses of computer and internet and weekly average time spent in computer and internet for non-academic purposes
Google (62.5\%), Wikipedia (39.6\%), YouTube (16.7\%), Yahoo (12.5\%), Face book (6.3\%) were the most visited sites for academic purposes. The other sites mentioned were studentconsult.com, eMedical, Opera Mini, medicalbooksfree.com, BMJ, Pub Med, MedicineNet and etc.

\begin{tabular}{lcc}
\hline${ }^{*}$ Non-academic uses of computer and internet $(\mathbf{n}=\mathbf{6 0 7})$ & & \\
\hline Watching movie & 400 & $66.0 \%$ \\
Listening music & 363 & $59.9 \%$ \\
Playing games & 265 & $43.7 \%$ \\
Chatting & 374 & $61.7 \%$ \\
Facebook & 501 & $82.7 \%$ \\
Others & 16 & $2.6 \%$ \\
\hline Weekly average time spent in computer and internet for non-academic purposes $(\mathbf{n}=604)$ \\
\hline Up to 3 hours/week & 192 & $32.2 \%$ \\
$4-6$ hours/week & 133 & $22.3 \%$ \\
$7-9$ hours/week & 83 & $13.9 \%$ \\
10 hours or more/week & 159 & $26.7 \%$ \\
Others & 37 & $6.2 \%$ \\
\hline
\end{tabular}

\footnotetext{
${ }^{*}$ Responses are more than $100 \%$ due to multiple responses.
}

Main non-academic uses of computer and internet were for Facebook (82.7\%), watching movies $(66 \%)$, chatting $(61.7 \%)$, listening to music $(59.9 \%)$, and playing games (43.7\%). Weekly average time spent by the respondents 
Table 4: Constraints of adequate use of computer and internet by the medical students ( $n=635$ )

\begin{tabular}{llc}
\hline $\begin{array}{l}\text { Constraints of adequate computer and internet use by medical } \\
\text { students }\end{array}$ & Frequency & Percentage $^{*}$ \\
\hline Inadequate number of PCs & 362 & $58.4 \%$ \\
Lack of time to use & 269 & $43.4 \%$ \\
IT not included in the syllabus & 261 & $42.1 \%$ \\
Lack of support from IT staff & 233 & $37.6 \%$ \\
No internet connectivity & 231 & $37.3 \%$ \\
Cost of use & 125 & $20.2 \%$ \\
Lack of knowledge about IT utility & 99 & $16.0 \%$ \\
Lack of skill to use IT & 55 & $8.9 \%$ \\
Others & 11 & $1.8 \%$ \\
\hline
\end{tabular}

* Responses are more than $100 \%$ due to multiple responses

The constraints of adequate computer and internet use as identified by the final year MBBS students were inadequate number of personal computers $(58.4 \%)$, lack of time to use $(43.4 \%)$, information technology not included in the syllabus $(42.1 \%)$, lack of support from IT staff (37.6\%), no internet connectivity (37.3\%), cost of use (20.2\%), lack of knowledge about IT utility $(16 \%)$, lack of skill to use IT $(8.9 \%)$.

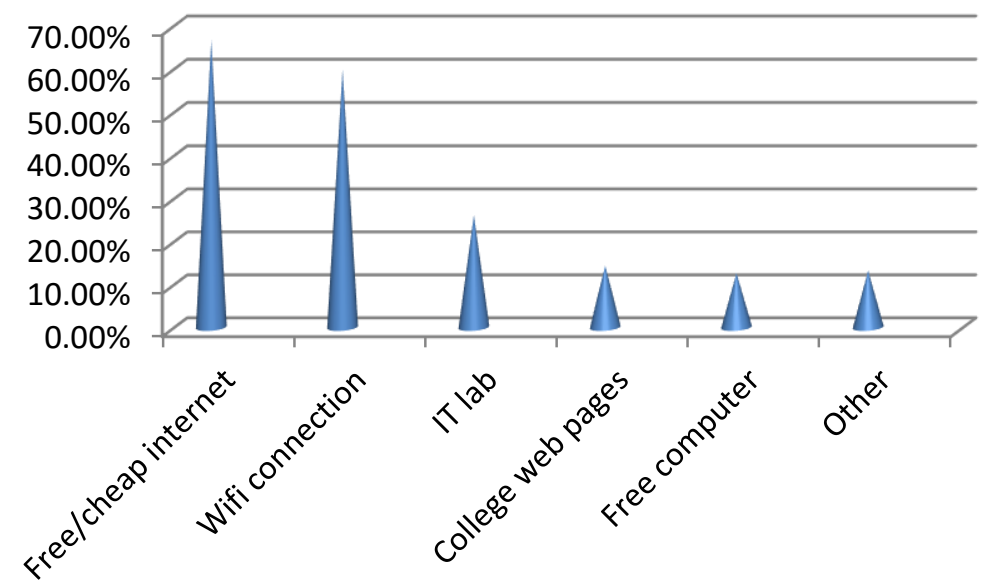

Figure-1: Opinion of the respondents about the use of computer and internet by medical students

In response to make open ended comments about the use of computer and internet by undergraduate students of Bangladesh, the respondents demanded free/cheap internet $(66.7 \%)$, Wi-Fi connection in the campus
(59.9\%), IT lab (26.1\%), college web pages $(14.4 \%)$, and free computers for the students $(12.6 \%)$ and others $(13.2 \%)$. The few opinions that were mentioned, were "wise use of IT", "use IT to become global", "sharing of ideas in 
web pages by the teachers and students" "inclusion of IT in curriculum" and "computer aided teaching".

\section{Discussion}

Out of the 659 respondents of this cross sectional survey, $52 \%$ were female and $48 \%$ were male, $83 \%$ had personal computer, $91 \%$ had computer access and $90 \%$ had internet access. Computer access in this study is lower than the undergraduate dental students of Jordan (Rajab \& Baqain, 2005) and Chile (Uribe \& Mariño, 2006). But it closely mimics with those of $95 \%$ undergraduate dental students in Oulu, Finland (Virtanen \& Nieminen ,2002), followed by $94 \%$ of medical students from Jeddah, Saudi Arabia (Mansor ,2002), 86.6\% of the dental students of Lagos, Nigeria (Butali,2011) and $84 \%$ of undergraduate students in Glasgow, United Kingdom (UK) (Jones, 1991).Computer access in this study is higher than those of $71.7 \%$ of first year medical students of Denmark (Dorup ,2004), 61\% medical students from Malaysia (Nurjahan et al., 2002) and $58.3 \%$ of the dental students of India (Kumar et al., 2009). Internet access of our final year MBBS students mimics closely with dental students of university of Jordan (100\%) (Rajab \& Baqain, 2005), medical students of Burla, India (80\%) (Mahraana et al., 2009 ), dental students and registrars of Lagos (95\%) (Butali, 2011) and Saudi Arabia (91.1\%) (Rahman, 2011). Computer and internet access to the medical students depend on multiple factors like institutional set up, curriculum need, cost of products and logistics, socio economic status, motivation and the time need. These factors may explain the variations of the results of the different studies in different period.

Majority (76.4\%) of them used computers for more than 3 years which is similar with a very recently published Saudi Arabian study (Rahman, 2011), but grossly dissimilar with the results obtained from studies in Manchester, Bristol and New Castle of UK, where 20\%, 14\% and $57 \%$ students respectively were reported to use the computer for more than three years (Grigg, 2001). This may be attributed to the fact that these three studies in UK were conducted more than a decade ago and the use of computer might have increased since then. A recent Jordanian (Rajab \& Baqain, 2005) and an Indian study (Kumar et al., 2009) reported that nearly one third of the students were using a computer for more than three years.

Majority (71.3\%) of the respondents mainly use computer for chatting. (Facebook and others) which is in strong contradiction with $91 \%$ of dental students of Jordan (Rajab \& Baqain, 2005) using computer for academic activities. A survey among the pre final and final year medical students of South India (Unnikrishnan et al., 2008) revealed that their main uses of computer are for entertainment (54.5\%), general information (25.5\%), thesis and research $(14.5 \%)$. At present, there are no curriculum bindings to the academic use of computer for medical students. Such nonacademic uses of computer by our students could be reduced if their teaching, assignments and assessment incorporated IT.

Purposes of internet use by the respondents were entertainment (84.1\%), collection of general information (75.9\%), reading newspapers $(32.6 \%)$, thesis and research $(15.1 \%)$ and others (7.5\%). These findings are more or less similar to the findings of Mahraana et al., (2009). Kumar, (2012) reported the purposes of using the internet by the medical students in India as literature searching $(65.95 \%)$, email $(63.82 \%)$, chatting $(34.04 \%)$, and academic reading $(31.91 \%)$ (Kumar, 2012). Ajuwon, (2003) also reported that email $(73.4 \%)$ and web browsing $(26.6 \%)$ were the main uses of internet by the medical students of Nigeria.

Multimedia/power point use (61.2\%), internet literature search (42.3\%), presentations $(25.8 \%)$, and word processing (23.2\%) reported. The highest used feature of computer was Internet (85.8\%) (Rajab \& Baqain, 2005), Internet (60.4\%) (Kumar, 2012), MS power point (61.06\%) (Rahman, 2011), Internet $(85.7 \%)$ (Butali, 2011) and word processing (55\%) (Nurjahan et al., 2002). Weekly average time spent by the respondents in computer and internet for academic purposes were up to 3 hours (51.5\%), 4-6 hours (18.2\%) and 10 hours or more $(9.0 \%)$ which was consistent with an South Indian study (Unnikrishnan et al., 2008) where $63 \%$ of the pre final and final year MBBS students spent up to 3 hours in a week with computer and online for academic purposes. Computer and internet use for academic purposes would be greatly enhanced only if it is integrated in the curriculum and assessment system.

The respondents mentioned Google (62.5\%), Wikipedia (39.6\%), YouTube (16.7\%), Yahoo (12.5\%) and Facebook (6.3\%) as their mostly visited sites/webs for academic purposes. This simulates closely with that dental college students of Saudi Arabia (Rahman, 2011) and Jordan (Rajab \& Baqain, 2005) where PubMed and Hotmail MSN were also the other leading 
sites they used to visit. Our students used mostly the free sites rather than the pay sites due to lack of access to the pay sites.

In this study, main non-academic use of computer and internet was logging into Facebook $(82.7 \%)$, Other than that watching movies (66\%), chatting (61.7\%), listening to music $(59.9 \%)$, and playing games $(43.7 \%)$ identified. Weekly average time spent by the respondents with computer and internet for non-academic purposes were up to 3 hours (32.2\%), 10 hours or more (26.7\%), 4-6 hours $(22.3 \%)$ and $7-9$ hours $(13.9 \%)$ which was contradictory to a South Indian study (Unnikrishnan et al., 2008) where $65.6 \%$ of prefinal and final year MBBS students spent 1 2 hours a week, $23.5 \%$ spent $2-3$ hours and $11 \%$ spent more than 3 hours. The vast majority of students in our study used the computer and internet for entertainment. The increasing use of social network sites as a virtual means of communication by the students may be a possible explanation. These findings raise the question whether internet and computer are a distracting media to our students as they misuse these resources spending a lot of academic hours with computer and internet for non-academic purposes. Similar results were also reported in a previous study (Walmsley et al., 2003).

The main constraints of adequate computer and internet use as identified by the final year MBBS students of this study were inadequate number of personal computers $(58.4 \%)$, lack of time to use $(43.8 \%)$, information technology not included in the syllabus $(42.1 \%)$, lack of support from IT staff $(37.6 \%)$, no internet connectivity $(37.3 \%)$, cost of use $(20.2 \%)$ etc. The identified constraints of this study were similar with those identified by Kumar et al. (2012) and Maharana et al. (2009) in Indian context. The social, economic and demographic similarity between these two countries may explain the similarities of constraints of adequate IT use in the medical colleges.

Students recommended the facilities to be available were free internet access, provision of adequate number of good quality PCs, Wi-Fi connection in the campus, IT laboratory and adequate support from IT staff, college web pages, free computers for the students etc. These recommendations are the solutions for the constraints that they identified regarding inadequate IT use in the medical colleges of Bangladesh. This finding mimics with the results of the study among the medical students of Orissa, India (Maharana et al., 2009). The similar socio- economic condition of Indian province, Orissa and Bangladesh may be the reason of such similar results.

\section{Limitations}

1. This study was done among the final year MBBS students of the eight randomly selected medical colleges of Bangladesh. So, the results may limit the potential for generalization of all undergraduate medical students of Bangladesh.

2. Students who were absent during the lecture class of data collection were not revisited. Overall response rate among all the enrolled students was $74.4 \%$. So, data collected in a single visit may not be representative of the whole class.

3. There was a reasonable number of missing values in the data collection sheet which may make the outcome of the study questionable.

4. There might be human error during data entry, analysis and interpretation.

\section{Conclusion}

The use of computer and internet is rapidly becoming a key component of medical education in many parts of the world. The results of this study indicate that most of the undergraduate medical students of Bangladesh had access and orientation to computer and internet. Most of the accesses and uses were the result of their individual initiative. The vast majority of our final year MBBS students used the computer and internet for entertainment. Moreover, 'the academic use of these technologies is only sporadic and yet to be established among the undergraduate medical students of Bangladesh. Such non- academic uses of computer by our students could be reduced if their teaching, assignments and assessment incorporated with IT. Certain constraints of adequate use of computer and internet by the students had been identified in the present study which need to be looked at. Government and institutional initiative would help overcome these constraints and bring their recommendations into reality. Provision of structured computer and Information Technology training and its inclusion into the MBBS curriculum, setting up of IT lab and elibrary would equip them with the skills they need to practice up to date and evidence based medicine in future, which are essential to improve the quality of medical care.

\section{References}

Ajuwon,G.A. (2003) Computer and internet use by first year clinical and nursing students in a 
Nigerian teaching hospital, BMC Medical Informatics and Decision Making, 3, 1, p.10.

Butali, A., Adeyemo, W.L., Akinshipo, A.O.,Fashina, A. \& Savage, K.O. (2011) Use of information and communication technology among dental students and registrars at the faculty of dental sciences, University of Lagos, Nigerian Journal of Clinical Practice, 14,4, pp .467-472.

Dorup,J. (2004) Experience and attitudes towards information technology among first year medical students in Denmark: longitudinal questionnaire survey, Journal of Medical Internet Research, 6, 1.

Drury, P. (2005) E-health: A model for developing countries, Health International, 2, 2) pp.19-26.

Feliciani, F. (2003) Medical care from space: Telemedicine, European Space Agency Bulletin, 114 , pp.54.

Grigg, P., Macfarlane,T.V., Shearer, A.C., Jepson, N.J.A. \& Stephens, C.D. (2001) Computing facilities available to final year students at 3 UK dental schools in 1997/8; their uses and students' attitude to information technology, European Journal of Dental Education, 5, 3, pp.101-108.

Harden, M.D.R. (2001) $\mathrm{E}$ is for everything in elearning, Medical Teacher, 23, 5, pp.441- 444.

Harden, R.M. (2002) Development in outline based education, Medical Teacher, 24, 2, pp. 117-120.

Jones, R.B., Navin, L.M., Barrie, J., Hillan, E. \& Kinane, D. (1991) Computer literacy among medical, nursing, dental and veterinary undergraduates, Medical Education, 25, 3 ,pp. 191-195.

Kumar, P. (2012) Application of information and communication technology (ICT) by medical students: A study of Government Medical College, Chandigarh, India, International Journal of Library and Information Science, 4, 3, pp. 45-51.

Kumar, S., Balasubramanyam, G., Duraiswamy, P. \& Kulkarni, S. (2009) Information technology practices amongst dental undergraduate students at a private dental institution in India, Journal of Dentistry of Tehran University of Medical Sciences, 6,3, pp.130-138.

Maharana, B., Biswal, S. \& Sahu, N.K. (2009) Use of information and communication technology by medical students: A survey of VSS Medical College, Burla, India, Library Philosophy and Practice (e-journal), pp.281.

Mansoor, I. (2002) Computer skills among medical learners: a survey at King Abdul Aziz University, Jeddah, Journal of Ayub Medical College, Abbottabad, 14, 3, pp.13-15.

Masood, S.A.N.O.B.E.R, Khan, R.A. \& Waheed, G.U.L.F.R.E.E.N. (2010) Computer literacy among the medical staff at Avicenna medical college and hospital, Journal of Nursing Economy, 16,2, pp.33.
Mattheos, N., Nattestad, A., Attstrom, R., Eaton,K . \& Feeny, L. (2001) Dissemination and the Net. In:Shanley D, editors. Dental education in Europe: towards convergence, Budapest: Dntal Press Kft; ,pp. 132-139.

Mooney, G.A. \& Bligh, J.G. (1997) Information technology in medical education: Current and future applications, Postgraduate Medical Journal, 73, 865, pp.701-704.

Myers, M.B. (2003) Telemedicine: an emerging health care technology, The Health Care Manager, 22, 3, pp.219-223.

Nurjahan, M.I., Lim, T.A., Yeong, S.W., Foong, A.L. \& Ware, J. (2002) Utilization of information technology in medical education: a questionnaire survey of students in a Malaysian institution, The Medical Journal of Malaysia, 57, pp.58-66.

Otto, A., Kushniruk, A., Ho, K., Joe, R. \& Borycki, E. (2009) Incorporation of medical informatics and information technology as core components of undergraduate medical education- time for change , Studies In Health Technology And Informatics, 143, pp.62-67.

Poelmans, S., Truyen, F. \& Deslé, R. (2009) Perceived computer literacy among different types of undergraduate students: Findings of a survey. 2nd International Conference of Education, Research, and Innovation, 16-18 November, 2009, Madrid, Spain.Availablle at: http://library.iated.org/view/POELMANS2009PE

Rahman, G. (2011) Use of computers among students of dental college in Saudi Arabia, Journal of Education And Ethics In Dentistry, 1,1, p.12.

Rajab, L. D. \& Baqain, Z. H. (2005) Use of information and communication technology among dental students at the University of Jordan, Journal of Dental Education, 69, 3, pp. 387- 398.

Seago, B, L., Schlesinger, J.B. \& Hampton, C.L. (2002) Using a decade of data on medical student computer literacy for strategic planning, Journal Of The Medical Library Association, 90,2 , p. 202.

Skinner, H., Biscope, S. \& Poland, B. (2003) Quality of internet access: barrier behind internet use statistics, Social Science \& Medicine, 57, 5, pp.875- 880 .

Unnikrishnan, B., Kulshrestha, V., Saraf, A., Agrahari, A.C., Prakash, S., Samantaray, L. \& Parida, A. (2008) Pattern of computer and internet use among medical students in Coastal South India, South East Asian Journal of Medical Education, 2, p.2.

Uribe, S. \& Mariño, R.J. (2006) Internet and information technology use by dental students in Chile, European Journal of Dental Education, 10,3, pp.162-168.

Walmsley, A.D., White, D.A., Eynon, R. \& Somerfield, L. (2003) The use of the Internet within 
Influence of exposure to specialties on career choice

a dental school, European Journal Of Dental Education, 7, 1, pp.27-33.

Virtanen, J.I. \& Nieminen, P. (2002) Information and communication technology among undergraduate dental students in Finland, European Journal of Dental Education,6, 4 , pp.147-152. 